\title{
Dipyridamole thallium-201 scintigraphy for early risk stratification of patients after uncomplicated myocardial infarction
}

Joseph Hung, Mehdi Moshiri, Geoffrey N Groom, Agatha A Van der Schaaf, Richard W Parsons, Mark E Hands

\begin{abstract}
Objective-To determine the safety and prognostic value of dipyridamole thallium-201 scintigraphy performed in patients within three to five days of acute myocardial infarction, including those receiving thrombolytic treatment.
\end{abstract}

Design-A prospective study of dipyridamole thallium-201 scintigraphy in patients early after acute myocardial infarction. Setting-University hospital.

Patients-200 patients who were clinically uncomplicated at day 3 after infarction, 92 $(46 \%)$ of whom had received thrombolysis. Main outcome measures-Incidence of cardiac death, non-fatal reinfarction, readmission to hospital for unstable angina, or non-elective revascularisation procedure within six months' follow up.

Results-No patient had a serious complication from the dipyridamole study. At six month follow up, 55 patients $(28 \%)$ had suffered a defined cardiac event. Patients who received thrombolysis had the same extent of thallium-201 redistribution and the same occurrence of subsequent cardiac events as those not receiving thrombolysis. Patients who subsequently had an event had more myocardial segments showing thallium-201 redistribution than event free patients: 2.7 (SD 1.9) $v 1.2$ (1.4), respectively $(p<0.001)$. Among all clinical and scintigraphic variables, multivariate analysis identified the extent of thallium-201 redistribution as the only independent predictor of outcome $(p<0.001)$. Among 63 patients $(32 \%)$ of the study cohort who showed more than two myocardial segments with thallium201 redistribution, the adjusted risk ratio for a cardiac event was 7.5 (95\% confidence interval 2.9 to 19.1 ) compared with patients without any redistribution.

Conclusions-Dipyridamole thallium-201 scintigraphy can be performed safely within a few days of the event in patients with uncomplicated myocardial infarction, including those who received thrombolysis, and can identify a subgroup of patients at high risk of future ischaemic events.

(Heart 1997;78:346-352)

Keywords: dipyridamole; thallium; myocardial infarction; prognosis
Early non-invasive risk evaluation of patients after myocardial infarction is helpful in identifying those who need expeditious angiography and coronary intervention and, conversely, those who are safe to be discharged early from hospital. Routine thrombolytic treatment has potentially increased the need for early assessment, as thrombolysis can result in more residual jeopardised myocardium and an increased risk of later ischaemic events. ${ }^{1-3}$ While complications such as heart failure or recurrent angina identify high risk patients after infarction, a more frequent clinical problem is the identification of initially asymptomatic patients who are at potential risk of later cardiac events. $^{4-6}$ Many studies have established the safety and prognostic value of a low level exercise electrocardiography test before hospital discharge or a symptom limited test a few weeks later in clinically uncomplicated patients. $^{7-11}$ Thallium-201 scintigraphy with exercise adds to the sensitivity of detection of residual ischaemia and future cardiac events. ${ }^{12-14}$ However, pharmacologically induced coronary vasodilatation by dipyridamole has also been shown to be as effective as maximal exercise testing in creating regional myocardial perfusion abnormalities detected by thallium-201 imaging. ${ }^{15}{ }^{16}$ Unlike rigorous exercise, dipyridamole infusion normally causes only a small increase in myocardial oxygen consumption, ${ }^{15}{ }^{16}$ and it may therefore be safer than exercise testing within a few days of acute infarction. It is also more widely applicable since it can be performed regardless of the patient's capacity to exercise or of concurrent $\beta$ blocker use.

Dipyridamole induced thallium-201 redistribution has been reported to identify patients at increased ischaemic risk after uncomplicated myocardial infarction. ${ }^{17-21}$ However, the overall patient experience has been small, dipyridamole thallium-201 scintigraphy was usually performed relatively late (nine or 10 days) after myocardial infarction, and few patients who had thrombolysis were included in these studies. ${ }^{17-21}$ This present study was therefore designed to evaluate prospectively the safety and prognostic value of early dipyridamole thallium-201 scintigraphy, performed within three to five days after an uncomplicated myocardial infarction in a cohort of 200 consecutive patients, almost half of whom received thrombolysis. 
Table 1 Comparison of clinical characteristics between patients in the study cohort and patients who were study eligible but not enrolled

\begin{tabular}{lcc}
\hline Demographics & $\begin{array}{c}\text { Study eligible patients } \\
\text { non-enrolled (n=129) }\end{array}$ & $\begin{array}{c}\text { Study cohort patients } \\
(n=200)\end{array}$ \\
\hline Age (years (SD)) & $60(10)$ & $58(10)$ \\
Male (n (\%)) & $98(76)$ & $168(84)$ \\
Previous AMI (n (\%)) & $28(22)$ & $33(17)$ \\
Chronic angina (n (\%)) & $13(10)$ & $29(15)$ \\
Previous CABG/PTCA (n (\%)) & $8(6)$ & $13(7)$ \\
Diabetes mellitus (n (\%)) & $11(9)$ & $16(8)$ \\
Hypertension (n (\%)) & $57(44)$ & $77(39)$ \\
Current smoker (n (\%)) & $49(38)$ & $83(42)$ \\
Anterior AMI (n (\%)) & $41(32)$ & $73(37)$ \\
Inferior AMI (n (\%)) & $79(61)$ & $113(57)$ \\
Non-Q wave MI (n (\%)) & $29(22)$ & $69(34)^{\star}$ \\
Thrombolytic treatment (\% (SD)) & $49(38)$ & $92(46)$ \\
Peak CK (units/l (SD)) & $1824(1384)$ & $1780(1436)$ \\
Inhospital death (n (\%)) & $1(0.8)$ & $0(0)$ \\
\hline
\end{tabular}

(A)MI, (acute) myocardial infarction; CABG, coronary artery bypass grafting; CK, creatine kinase; PTCA, percutaneous transluminal coronary angioplasty.

${ }^{\star} \mathrm{P}=0.03$; study eligible, non-enrolled patients $v$ study cohort.

\section{Methods}

SUBJECTS

The study population consisted of 200 patients (168 men and 42 women), aged 75 years or less, mean (SD) 58 (10) years, in whom we performed dipyridamole thallium-201 scintigraphy three to five days (mean four days) after acute myocardial infarction (table 1). The study cohort was recruited from 391 consecutive acute myocardial infarction patients admitted to the coronary care unit of Sir Charles Gairdner Hospital between March 1991 and November 1992. This study was approved by the human ethics committee of the University of Western Australia and all study participants gave their written informed consent. Acute myocardial infarction was confirmed by a history of ischaemic chest pain, a typical rise and fall of creatine kinase and creatine kinase isoenzyme (MB), and the appearance of new $\mathrm{Q}$ waves, evolving ST-T wave changes, or left bundle branch block on the electrocardiogram.

Study exclusions comprised 62 patients $(16 \%)$ who had severe heart failure $(\mathrm{n}=17)$, recurrent angina $(\mathrm{n}=30)$, or persistent arrhythmias, including second or third degree atrioventricular block $(n=15)$, on day 3 after infarction. Patients would also have been excluded if they had severe reactive airways disease requiring continued treatment with xanthine derivatives, although none of our patients was excluded on that basis. Of the study eligible patients, 129 (33\%) were considered suitable for dipyridamole study but could not have the thallium-201 scan since it was unavailable during the defined time window for study $(\mathrm{n}=108)$, or they failed to give informed consent $(n=21)$. The resultant study population comprised 200 patients, 73 (37\%) with anterior infarction, 69 (34\%) with non-Q-wave infarction, and $92(46 \%)$ who received thrombolysis with either streptokinase or tissue plasminogen activator (table 1). The clinical characteristics of the study cohort were similar to the study eligible, non-enrolled patients except for a higher prevalence of non-Q-wave infarction in the former (table 1). There was only one in-hospital death among the 329 study eligible patients $(0.3 \%)$ compared with 13 in-hospital deaths $(21 \%)$ among the 62 patients whose course was clinically complicated by day 3 after infarction and who were excluded from the dipyridamole study $(\mathrm{p}<0.001)$.

DIPYRIDAMOLE THALLIUM-201 STUDY

All studies were performed in the nuclear medicine department using a standard small field of view scintillation camera (Technicare Sigma 420, Solon, Ohio, USA). The patients remained on their usual cardiac drugs, except for nitrates which were withdrawn for at least six hours before the study. At the time of study, 162 patients $(81 \%)$ were on $\beta$ blockers and 60 $(30 \%)$ were on a calcium channel blocker. A standard dipyridamole infusion protocol was used. ${ }^{15}{ }^{16}$ With the patient supine, dipyridamole was infused intravenously at a rate of 0.14 $\mathrm{mg} / \mathrm{kg} / \mathrm{min}$ over four minutes for a total dose of $0.56 \mathrm{mg} / \mathrm{kg}$. Thallium-201 (2.0 mCi) was injected three minutes after completion of dipyridamole infusion. A 12 lead electrocardiogram, heart rate, and blood pressure were recorded at baseline and every two minutes for 14 minutes. Aminophylline 50 to $100 \mathrm{mg}$ was given intravenously if patients developed prolonged chest pain or had severe flushing, headache, or tachycardia. Imaging was started seven to eight minutes after thallium-201 injection. Standard eight minute planar $35^{\circ} \mathrm{left}$ anterior oblique, anterior, and $70^{\circ}$ left anterior oblique images were acquired and repeated in the same sequence three to four hours later, 30 minutes after thallium-201 reinjection $(1.0 \mathrm{mCi})$.

THALLIUM-201 IMAGE ANALYSIS

Background subtracted planar thallium images were visually assessed, along with computer derived circumferential profiles. ${ }^{22}$ For the purpose of this study the left ventricle was divided into five segments in each projection (fig 1). Each segment was assigned a score of 0 to 3, depending on the thallium-201 activity $(0=$ normal activity, $1=$ mild reduction, $2=$ moderate reduction, $3=$ severe reduction). All scans were read and scored independently by two experienced nuclear medicine physicians and by consensus where there was initial disagreement. Segmental perfusion defects were defined as showing thallium-201 redistribution if the defect score decreased by one or more grade between the initial and reinjection study. The myocardial segment showing redistribution was classified as being within or outside the infarct zone, based on its relation to the electrocardiographic site of infarction. However, a thallium-201 defect occurring in the apical segment was always assigned to the infarct territory. The number of myocardial segments showing thallium-201 redistribution was also recorded out of the total nine non-overlapping segments in the three projections (fig 1).

\section{RADIONUCLIDE VENTRICULOGRAPHY}

Resting equilibrium gated radionuclide ventriculography was performed in 195 (98\%) of the patients at a mean of 11 (SD 5) days after acute myocardial infarction. In vitro labelling of the patient's erythrocytes was obtained using technetium-99m. A scintillation camera (Technicare Sigma 420) with a slant hole collimator 
$70^{\circ} \mathrm{LAO}$

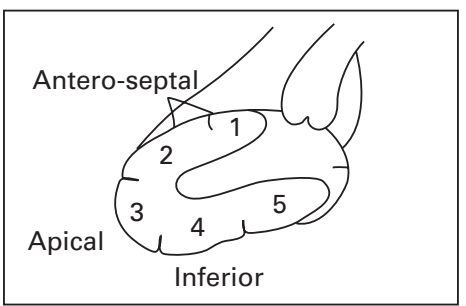

Anterior

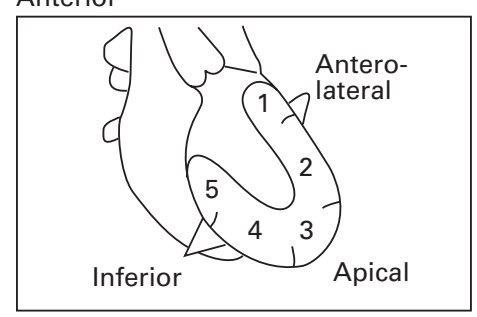

$35^{\circ} \mathrm{LAO}$

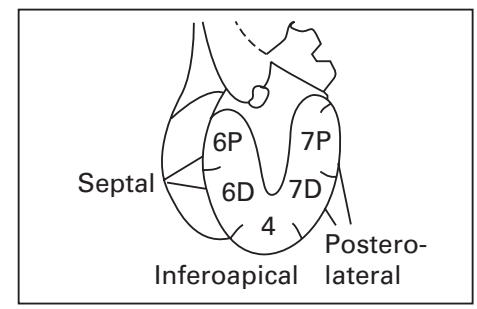

Thallium activity in each segment

$$
\begin{aligned}
& 0=\text { normal } \\
& 1=\text { mild reduction } \\
& 2=\text { moderate reduction } \\
& 3=\text { severe reduction }
\end{aligned}
$$

Figure 1 Schematic diagram showing myocardial thallium profiles in the $35^{\circ}$ left anterior oblique, anterior, and $75^{\circ}$ left anterior oblique projections. The individual myocardial segments in each projection and the scoring of thallium activity in each myocardial segment are also shown. LAO, left anterior oblique.

was used and imaging of the left ventricular blood pool was performed in the left anterior oblique position. The counts were collected as a histogram, using synchronisation with the $\mathrm{R}$ wave on the ECG, and were stored in a computer with 24 images per cardiac cycle and a minimum of $7 \times 10^{6}$ counts per image. Left ventricular ejection fraction was calculated by methods previously described. ${ }^{23}$

FOLLOW UP

Clinical follow up was obtained on all patients at six months after hospital discharge. Cardiac events were defined as cardiac death, non-fatal reinfarction, and hospital admission for unstable angina. Subsequent coronary bypass graft surgery $(\mathrm{CABG})$ or percutaneous transluminal coronary angioplasty (PTCA) was also a defined cardiac event but only if it was non-elective, that is, if it was needed because of unstable or recurrent angina. Cardiac events were further confirmed by hospital medical records.

\section{DATA ANALYSIS}

Results are expressed as mean (SD). Twogroup comparisons for continuous variables were made by Student's $t$ test. Frequencies were compared by $\chi^{2}$ analysis. Multivariate stepwise logistic regression analysis was used to determine independent predictors of defined cardiac events. Statistical significance was taken at $p \leqslant 0.05$. Analyses were performed using SAS (version 6.07; SAS Institute, Cary, North Carolina, USA, 1991) and EGRET epidemiological computer package (version 0.26.6; SERC, Seattle, Washington, 1990).

\section{Results}

CLINICAL RESPONSES TO DIPYRIDAMOLE

Intravenous dipyridamole increased heart rate from 65 (11) to $74(12)$ beats $/ \mathrm{min}(\mathrm{p}<0.001)$. Systolic blood pressure was unchanged by dipyridamole: 120 (17) mm Hg before admin-
Table 2 Clinical responses during dipyridamole thallium-201 study $(n=200)$

\begin{tabular}{lc}
\hline Chest pain & $28(14.0)$ \\
ST $\downarrow \geq 0.1 \mathrm{mV}$ & $11(5.5)$ \\
ST $\uparrow \geq 0.1 \mathrm{mV}$ & $6(3.0)$ \\
Chest pain or ST $\downarrow \uparrow \geq 0.1 \mathrm{mV}$ & $36(18.0)$ \\
Headache & $15(7.5)$ \\
Flushing & $9(4.5)$ \\
Aminophylline given & $26(13.0)$ \\
\hline Values are n (\%). & \\
ST $\downarrow$, ST segment depression; ST $\uparrow$, ST segment elevation.
\end{tabular}

istration and 120 (19) $\mathrm{mm} \mathrm{Hg}$ after (NS). Side effects including chest pain, headache, or severe flushing occurred in a minority of patients (table 2). A possible ischaemic response with chest pain or $0.1 \mathrm{mV}$ or greater ST segment deviation occurred in 36 patients $(18 \%)$. Aminophylline was given for control of side effects in 28 patients (14\%). Dipyridamole infusion did not cause any major complications, including nonfatal infarction, serious arrhythmia, cardiac arrest, or death.

\section{SCINTIGRAPHIC RESULTS}

A dipyridamole induced reversible thallium201 perfusion defect occurred in 123 patients $(62 \%)$ in the study cohort. Thallium-201 redistribution was seen within the infarct zone in 101 patients $(51 \%)$, and outside the infarct zone in $40(20 \%)$. More extensive reversible ischaemia as defined by more than two myocardial segments showing thallium-201 redistribution occurred in 63 patients $(32 \%)$. Patients who had dipyridamole induced chest pain or $\geqslant 0.1 \mathrm{mV} \mathrm{ST} \mathrm{segment} \mathrm{shift} \mathrm{compared}$ to those without an ischaemic response had a higher prevalence of thallium-201 redistribution: 28 of 36 (78\%) compared to 95 of 164 $(58 \%)$, respectively $(\mathrm{p}=0.04)$. The resting radionuclide left ventricular ejection fraction was $52(11) \%$ in the overall study population ( $\mathrm{n}$ $=195)$. A subnormal ejection fraction $(<46 \%)$ was present in 45 of these patients $(23 \%)$.

EFFECT OF THROMBOLYTIC TREATMENT

Clinical characteristics were not significantly different between patients who did and did not receive thrombolysis, except for a lower prevalence of current smokers $(p=0.02)$ and an expected higher prevalence of non-Q-wave infarction $(\mathrm{p}=0.002)$ in patients not given thrombolytic treatment (table 3 ). Thrombolytic treatment was associated with a greater peak creatine kinase release $(p<0.001)$, and a higher subsequent resting left ventricular ejection fraction $(p=0.008)$. However, the prevalence and extent of dipyridamole induced thallium-201 redistribution were not different between patients who did and did not receive thrombolysis (table 3).

PREDICTION OF CARDIAC EVENTS

Clinical follow up was available on all patients at six months after their myocardial infarction. At follow up, 55 (28\%) of the study cohort had experienced a cardiac event. These comprised two patients who died (both out of hospital sudden deaths), four with non-fatal reinfarctions, 10 readmitted to hospital for unstable angina, and 39 with recurrent or unstable 
Table 3 Comparison of clinical variables and scintigraphic results between patients who did or did not receive thrombolytic treatment

\begin{tabular}{lll}
\hline Variable & $\begin{array}{l}\text { No thrombolytic } \\
\text { treatment }(n=108)\end{array}$ & $\begin{array}{l}\text { Thrombolytic } \\
\text { treatment }(n=92)\end{array}$ \\
\hline Age (years (SD)) & $59(11)$ & $57(10)$ \\
Male (n (\%)) & $88(81)$ & $80(87)$ \\
Past AMI (n (\%)) & $21(19)$ & $12(13)$ \\
Chronic angina (n (\%)) & $15(14)$ & $14(15)$ \\
Past CABG/PTCA (n (\%)) & $10(9)$ & $4(4)$ \\
Hypertension (n (\%)) & $47(43)$ & $30(33)$ \\
Diabetes mellitus (n (\%)) & $9(8)$ & $7(8)$ \\
Current smoker (n (\%)) & $36(33)$ & $47(51)^{\star}$ \\
Anterior MI (n (\%)) & $41(38)$ & $32(35)$ \\
Non-Q wave MI (n (\%)) & $48(44)$ & $21(23) \dagger$ \\
Peak CK level (units/1 (SD)) & $1208(981)$ & $2452(1592) \ddagger$ \\
LVEF\% (n=195) (SD) & $50 \%(11)$ & $54 \%(11) \Phi$ \\
Infarct zone Tl redistribution (n (\%)) & $61(56)$ & $50(54)$ \\
Non-infarct zone Tl redistribution (n (\%)) & $25(23)$ & $15(16)$ \\
Number segments with Tl redistribution (SD) & $1.8(1.7)$ & $1.5(1.6)$ \\
$>$ 2 segments with Tl redistribution (n (\%)) & $35(32)$ & $28(30)$ \\
\hline
\end{tabular}

(A)MI, (acute) myocardial infarction; CABG, coronary artery bypass grafting; CK, creatine kinase; LVEF, left ventricular ejection fraction; PTCA, percutaneous transluminal coronary angioplasty; $\mathrm{Tl}$, thallium-201.

Patients not given $v$ those given thrombolytic treatment: ${ }^{\star} \mathrm{p}=0.02 ; \dagger \mathrm{p}=0.002 ; \ddagger \mathrm{p}<0.001$; S $=0.008$

Table 4 Clinical and scintigraphic predictors of cardiac events

\begin{tabular}{llll}
\hline & $\begin{array}{l}\text { Patients } \\
\text { without } \\
\text { cardiac events } \\
(n=145)\end{array}$ & $\begin{array}{l}\text { Patients with } \\
\text { cardiac } \\
\text { events } \\
(n=55)\end{array}$ & p value \\
Variable & $57(11)$ & $60(10)$ & 0.068 \\
\hline Age (years (SD)) & $121(83)$ & $46(84)$ & 0.778 \\
Males (n (\%)) & $51(35)$ & $26(47)$ & 0.204 \\
Hypertension (n (\%)) & $14(10)$ & $2(4)$ & 0.304 \\
Diabetes mellitus (n (\%)) & $19(13)$ & $14(25)$ & 0.026 \\
Past AMI (n (\%)) & $14(10)$ & $15(27)$ & 0.003 \\
Chronic angina (n (\%)) & $7(5)$ & $7(13)$ & 0.079 \\
Past CABG/PTCA (n (\%)) & $55(38)$ & $18(33)$ & 0.248 \\
Current smoker (n (\%)) & $57(39)$ & $16(29)$ & 0.238 \\
Anterior MI (n (\%)) & $50(34)$ & $19(35)$ & 0.874 \\
Non-Q wave MI (n (\%)) & $65(45)$ & $27(49)$ & 0.589 \\
Thrombolytic treatment (n (\%)) & $1902(1552)$ & $1459(1015)$ & 0.051 \\
Peak CK (units/1 (SD)) & $51 \%(11)$ & $55 \%(9)$ & 0.027 \\
LVEF \% (n=195) (SD) & & & \\
Dipyridamole induced chest pain (n (\%)) or & $22(15)$ & $14(25)$ & 0.091 \\
$\geq 0.1$ mV ST segment shift (n (\%)) & $78(54)$ & $45(82)$ & $<0.001$ \\
Any Tl redistribution (n (\%)) (n (\%)) & $68(47)$ & $43(78)$ & $<0.001$ \\
Infarct zone Tl redistribution (n) & $22(15)$ & $18(33)$ & 0.012 \\
Non-infarct zone Tl redistribution (n (\%)) & $1.2(1.4)$ & $2.7(1.9)$ & $<0.001$ \\
Number segments with Tl redistribution (SD) & $30(21)$ & $33(60)$ & $<0.001$ \\
$>2$ segments with Tl redistribution (n (\%)) & &
\end{tabular}

(A)MI, (acute) myocardial infarction; CABG, coronary artery bypass grafting; CK, creatine kinase; LVEF, left ventricular ejection fraction; PTCA, percutaneous transluminal coronary angioplasty; $\mathrm{Tl}$, thallium-201.

Table 5 Independent predictors of cardiac events on stepwise logistic regression analysis

\begin{tabular}{lllc}
\hline & & $\begin{array}{l}95 \% \text { Confidence } \\
\text { intervals }\end{array}$ & p value \\
\hline $\begin{array}{l}\text { Clinical variables alone entered } \\
\text { Chronic angina }\end{array}$ & 2.8 & 1.1 to 6.9 & 0.03 \\
$\begin{array}{l}\text { LVEF and site of Tl redistribution entered } \\
\text { Absent Tl redistribution }\end{array}$ & 1.0 & & \\
$\begin{array}{l}\text { Infarct zone Tl redistribution } \\
\text { Infarct and non-infarct zone Tl redistribution together }\end{array}$ & 2.8 & 1.2 to 6.6 & 0.02 \\
$\begin{array}{l}\text { Extent of Tl redistribution entered } \\
\text { Absent Tl redistribution } \\
\leqslant 2 \text { segments with Tl redistribution }\end{array}$ & 1.0 & 2.8 to 29.3 & $<0.001$ \\
$>2$ segments with Tl redistribution & 1.6 & 0.6 to 4.3 & 0.33 \\
\hline
\end{tabular}

LVEF, left ventricular ejection fraction; Tl, thallium-201.

angina requiring non-elective CABG (22 patients) or PTCA (17 patients). Six additional patients without recurrent angina had elective coronary revascularisation but were not regarded as having had a cardiac event for the prognostic assessment. The median time from initial myocardial infarction to any defined cardiac event was 40 days, range four to 176 days. The median times to non-elective CABG or PTCA were 55 days and 24 days, respectively, indicating that the coronary revascularisation procedures were generally not performed on the initial hospital admission.

Univariate predictors of cardiac events are shown in table 4. Among clinical variables, a history of chronic angina and past myocardial infarction was significantly more frequent in patients who had a subsequent event than in those without an event. Patients with subsequent events had also an initial smaller infarct on the basis of creatine kinase values ( $p=0.05$ ) and a higher resting left ventricular ejection fraction $(p=0.03)$. However, they had a higher prevalence of dipyridamole induced thallium201 redistribution both within and outside the infarct zones, and a greater number of myocardial segments showing thallium-201 redistribution $(p<0.001)$ (table 4). Patients who received thrombolysis compared to those not receiving thrombolysis had a similar incidence of subsequent cardiac events: $29 \%$ v 26\%, respectively (NS).

The variables shown in table 4 were then entered in a stepwise logistic regression analysis. Dipyridamole thallium variables were entered by site of thallium-201 redistribution (nil redistribution; infarct zone alone; noninfarct zone alone; and combined infarct and non-infarct zones), as well as by extent ( 0 segments; $\leqslant 2$ segments; and $>2$ segments). Independent predictors of cardiac events and their associated odds (risk) ratios are shown in table 5. With clinical variables alone, only a history of chronic angina was found to be an independent predictor of events $(p=0.03)$. After radionuclide left ventricular ejection fraction and site of dipyridamole induced thallium-201 redistribution were added to the model, the only significant predictors of outcome were thallium-201 redistribution in the infarct zone $(p=0.02)$ or in combined infarct and non-infarct zones $(\mathrm{p}<0.001)$. However, the site of thallium-201 redistribution was no longer significant when the extent of redistribution was added to the model, and the occurrence of more than two myocardial segments with redistribution was selected as the only independent predictor of events $(p<0.001)$. After adjustment for all other variables, patients with thallium-201 redistribution involving more than two myocardial segments had a risk ratio of 7.5 (95\% confidence interval 2.9 to 19.1 ) compared to those without any redistribution. Among the six patients who died or had recurrent non-fatal infarction, all had at least one segment of dipyridamole induced thallium-201 redistribution, and four had more than two segments of redistribution The sensitivity, specificity, positive predictive value, and negative predictive value for cardiac events of any dipyridamole induced thallium-201 redistribution were $82 \%, 54 \%, 37 \%$, and $87 \%$, respectively. For the occurrence of more than two myocardial segments with thallium-201 redistribution these values were $60 \%, 79 \%, 52 \%$, and $84 \%$, respectively. 
Table 6 Prognostic value of dipyridamole thallium-201 scintigraphy postinfarction

\begin{tabular}{|c|c|c|c|c|c|}
\hline Study & Patients (n) & $\begin{array}{l}\text { Mean time } \\
\text { after MI }\end{array}$ & $\begin{array}{l}\text { Mean follow up } \\
\text { (months) }\end{array}$ & Cardiac events & $\begin{array}{l}\text { Significant multivariate } \\
\text { predictors of cardiac events }\end{array}$ \\
\hline Leppo et $a l^{17}$ & 51 & $10-16$ days & 19 & $\mathrm{CD}, \mathrm{MI}$ & TD \\
\hline Pirelli et $a l^{18}$ & 35 & 9 days & 11 & $\mathrm{CD}, \mathrm{MI}$, new $\mathrm{AP}$ & TD \\
\hline Younis et al ${ }^{19}$ & $33 \dagger$ & 9 days & 12 & $\mathrm{CD}, \mathrm{MI}, \mathrm{UA}, \mathrm{CABG}$ & TD (1) Number VD (2) \\
\hline Gimple $e t a l^{20}$ & 40 & NA & 6 & $\mathrm{CD}, \mathrm{MI}, \mathrm{VF}, \mathrm{UA}$ & NIZ TD \\
\hline Brown et al ${ }^{21}$ & 50 & 2.6 days & 12 & CD, MI, UA & IZ TD \\
\hline Present study & 200 & 3-5 days & 6 & CD, MI, UA, CABG, PTCA & Extent TD \\
\hline
\end{tabular}

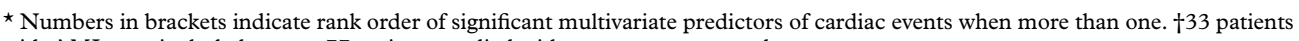
with AMI were included among 77 patients studied with acute coronary syndrome.

$\mathrm{AP}$, angina pectoris; $\mathrm{CABG}$, coronary artery bypass grafting; $\mathrm{CD}$, cardiac death; IZ, infarct zone; MI, myocardial infarction; NA, not available; NIZ, non-infarct zone; PTCA, percutaneous transluminal coronary angioplasty; TD, reversible thallium-201 defect; UA, unstable angina; $\mathrm{VD}$, vessel disease; $\mathrm{VF}$, ventricular fibrillation.

\section{Discussion}

There have been many papers on the value of non-invasive risk stratification of patients after myocardial infarction, with the majority of studies focused on exercise electrocardiographic testing, alone or in combination with thallium-201 scintigraphy. ${ }^{6-14}$ Most of these studies evaluated patients in the prethrombolytic era. There is a perceived need for earlier risk stratification in patients receiving thrombolysis, because of the potential for salvaged but jeopardised myocardium in these patients. However, in the first few days after infarction, exercise testing is usually not feasible or has questionable safety. At this period, pharmacological "stress" testing with dipyridamole is likely to be safer and more widely applicable since it can be performed in virtually all patients regardless of their exercise capacity or $\beta$ blocker use. Our study results confirm that dipyridamole thallium-201 scintigraphy can be performed safely within three to five days of uncomplicated myocardial infarction, and that it could identify a subgroup of patients at increased risk of future cardiac events. In fact, the extent of dipyridamole induced thallium-201 redistribution was a strong and sole independent determinant of prognosis in our study cohort.

This present study comprises almost as many patients as the previous published experience of dipyridamole thallium-201 scintigraphy in patients recovering after acute myocardial infarction (see summary of studies in table 6). Most studies were performed relatively late (nine or 10 days) after infarction, ${ }^{17-19}$ with the exception of that by Brown et $a l^{21}$ who studied patients at an average of 2.6 days after their infarct, but in a relatively small cohort of only $10 \%$ of the eligible study population (table $6)$. In our present large series of 200 patients, studied three to five days after uncomplicated acute myocardial infarction, no serious hazards - reinfarction, serious arrhythmia, cardiac arrest, or death-arose directly from the dipyridamole study. Intravenous dipyridamole, at a standard dose of $0.56 \mathrm{mg} / \mathrm{kg}$, produced only a small increase in heart rate and rate-pressure product, in keeping with previous reported experience. ${ }^{15} 16$ Symptomatic or electrocardiographic signs of ischaemia occurred in a minority (18\%) of patients, and resolved rapidly with aminophylline. As the sensitivity of dipyridamole thallium-201 scintigraphy is unaffected by concurrent antianginal treatment $(80 \%$ of patients were taking $\beta$ blockers), this increases the safety of testing at this early stage after infarction. Pronounced bronchospasm after dipyridamole was not observed, although patients with severe reactive airways disease unable to interrupt treatment with xanthine derivatives were excluded from study.

It should be emphasised that our study population represents a low risk group overall, consisting of patients who were clinically uncomplicated on the third day after infarction. ${ }^{4-6}$ Nevertheless, they comprised the majority $(84 \%)$ of our patients surviving infarction, and the challenge is to identify among them a number who are still at potential risk of adverse cardiac events. In our study patients, who had a normal left ventricular ejection fraction, residual ischaemia is the major determinant of prognosis, and such patients are most at risk of subsequent non-fatal ischaemic events, primarily reinfarction and unstable angina. Indeed, those patients whose course was subsequently complicated by a cardiac event had evidence of a smaller initial infarct but scintigraphic evidence of more residual ischaemia (table 4). As expected, these patients had a low mortality in the first six months (1.0\%; only two died), but a moderately high morbidity rate $(27 \% ; 53$ patients had reinfarction, unstable angina, or non-elective CABG or PTCA). Most of the cardiac events occurred in the first six weeks after infarction and it would have been useful to identify such patients for possible intervention before initial hospital discharge.

The high prevalence of thallium-201 redistribution detected in this present study (62\%) is compatible with results from previous studies using exercise, ${ }^{12-14}$ dipyridamole, ${ }^{17-21}$ or adenosine scintigraphy ${ }^{24}$ in postinfarction patients. Myocardial segments showing thallium-201 redistribution are thought to reflect viable but jeopardised myocardium, and can improve or normalise after revascularisation. ${ }^{25}$ We used a three to four hour thallium-201 reinjection protocol in order to enhance the distinction between viable myocardium and scar, since "irreversible" thallium defects on standard three to four hour redistribution images will often show some reversibility with thallium reinjection. ${ }^{26}$ As in other studies, scintigraphic redistribution occurred more often within than remote to the infarct zone. ${ }^{1213202124}$ This may reflect collateral supply to the infarct related occluded artery, ${ }^{24}$ and the relatively high proportion of our patients who had non-Q- 
wave myocardial infarction (34\%) or thrombolytic treatment $(46 \%)$. However, periinfarctional ischaemia, if extensive, and distant ischaemia have both been found to be important determinants of prognosis. ${ }^{27}$ Increased thallium-201 lung uptake and transient left ventricular dilatation have also been found to be of prognostic value in exercise thallium-201 scintigraphy after infarction ${ }^{12}$ but were not reported in previous prognosis studies using dipyridamole ${ }^{17-21}$ or adenosine thallium-201 scintigraphy. ${ }^{24}$ These scintigraphic abnormalities generally reflect severe myocardial ischaemia. However, increased thallium-201 lung uptake after dipyridamole has not been found to predict the extent or severity of coronary artery disease. ${ }^{15}$ In our clinical experience significant left ventricular dilatation is not often seen after dipyridamole infusion, probably because instead of producing true myocardial ischaemia, dipyridamole mainly causes regional myocardial perfusion abnormalities associated with hyperaemia, which are detected by thallium-201 imaging. ${ }^{15}$ This is likely to have been the case in our patients, most of whom were on $\beta$ blockers at the time of study.

Our study confirms that dipyridamole induced thallium redistribution is the most important determinant of prognosis after uncomplicated myocardial infarction, in agreement with previous smaller studies (table 6). It should be emphasised that these patients were clinically uncomplicated early after infarction, and no clinical characteristic could readily identify their subsequent risk. We found that redistribution both within and outside the infarct territory, but particularly when it occurred in both, was a significant determinant of prognosis. However, on multivariate analysis it was the extent rather than the site of redistribution that was the more significant predictor (table 5). Of the 63 patients from the study cohort $(32 \%)$ who showed more than two myocardial segments with thallium redistribution, 33 $(52 \%)$ had a subsequent cardiac event, and the adjusted risk ratio of an event was 7.5 (95\% confidence interval 2.9 to 19.1 ) compared to those without redistribution. Of the 137 patients without this risk predictor, 115 (84\%) remained event-free, and 67 of the 77 patients $(87 \%)$ without any dipyridamole induced thallium redistribution remained event-free. While coronary angiography was not directly compared with thallium imaging, previous studies have suggested that angiographic findings alone may not be a good predictor of future cardiac events after infarction. ${ }^{128}$ As an adjunct to angiography, thallium-201 scintigraphy can define the extent of myocardium perfused by a given coronary artery and the functional significance of a coronary stenosis, and it can distinguish scar from viable, jeopardised myocardium.

Most studies of non-invasive testing in the postinfarction population were performed before the era of routine thrombolytic treatment. ${ }^{6}{ }^{11}$ Successful thrombolysis might be expected to salvage myocardium but with a potentially increased risk of residual ischaemia. Nearly half of our study cohort received thrombolysis, and as expected these patients had a greater creatine kinase release and a higher subsequent left ventricular ejection fraction than patients not given thrombolysis (table 3). Some but not all randomised trials have shown an increased risk of reinfarction and recurrent angina in patients receiving thrombolysis compared to placebo. ${ }^{12}$ In this present study, patients who received thrombolysis had the same scintigraphic prevalence and extent of residual ischaemia and a similar incidence of later ischaemic events as those who did not have thrombolysis (table 3 ). While this may appear surprising, thrombolysis may also reduce the risk of subsequent ischaemia, as it not uncommonly achieves patency of the infarct related artery without a severe residual stenosis. ${ }^{29}{ }^{30}$ Although early invasive investigation is often urged in patients who receive thrombolysis, the TIMI study indicated that a strategy of coronary angiography performed 18 to 48 hours after thrombolysis and followed by prophylactic coronary angioplasty offered no advantages over a more conservative strategy in which these procedures were provided only to those with recurrent ischaemia. ${ }^{30}$ In this respect, dipyridamole thallium-201 imaging may prove to be a useful approach in deciding who should proceed to early angiography and coronary intervention after thrombolysis.

\section{STUDY LIMITATIONS}

We used planar rather than single photon emission computed tomographic (SPECT) thallium-201 imaging, as the latter was not available in our laboratory at the time the study was begun. Compared with planar thallium imaging, SPECT is more sensitive to individual diseased arteries, and is inherently more quantitative. ${ }^{31}$ Nevertheless, using planar imaging with a thallium reinjection protocol we were able to detect redistribution with the same frequency as a previous study with SPECT imaging. ${ }^{24}$ While SPECT imaging should prove to be useful, particularly for better quantitation of the myocardial territory at risk, an increased sensitivity may not necessarily have improved the positive predictive value of the test, since only large redistribution was found to be prognostically important. Cardiologists were allowed access to test results, which may have influenced their decisions over coronary intervention in their patients. However, to try to reduce this bias we had decided that only nonelective CABG or PTCA performed for unstable or recurrent angina should be included as cardiac events. The median time to intervention in these patients indicated that coronary interventions were generally not related to the initial hospital admission, and they were not primarily influenced by the scintigraphic results. Finally, in our large study population the number of subsequent "hard" cardiac events (cardiac death or non-fatal reinfarction) was low, as would be expected in patients who were clinically uncomplicated by the third day after infarction. Nevertheless these represent the majority of patients surviving acute myocardial infarction ( $84 \%$ in our study), in their further 
stratification into moderately high risk or very low risk subsets is thought to be of value..$^{4-6}$

CLINICAL IMPLICATIONS

Our study shows that dipyridamole thallium201 scintigraphy is safe to perform within the first few days after uncomplicated myocardial infarction and that the extent of thallium-201 redistribution is a strong independent predictor of future ischaemic events in these otherwise low risk patients. Dipyridamole thallium201 scintigraphy is easier and more widely applicable than exercise testing in the first few days after acute myocardial infarction. Consequently, it should prove to be useful in the early non-invasive risk evaluation of postinfarction patients, including those who have received thrombolytic treatment.

This study was supported by a National Heart Foundation grant-in-aid (G90P3194), ACT, Australia. We would like to acknowledge Debra Herring and Elsie Yu for their invaluable assistance during the study. We would also like to thank members of the Departments of Cardiovascular Medicine and Nuclear Medicine for their cooperation and technical assistance throughout the study.

1 AIMS Trial Study Group. Long-term effects of intravenous anistreplase in acute myocardial infarction: final report of the AIMS study. Lancet 1990; 335:427-31.

2 Schroder R, Neuhaus K-L, Linderer T, Leizorovicz A, Wegscheider K, Tebbe U. Risk of death from recurrent ischemic events after intravenous streptokinase in acute myocardial infarction: results from the Intravenous Streptokinase in Myocardial Infarction (ISAM) study. Circulation 1987; 76(suppl II):II-44-51.

3 Stone GW, Grines CL, Browne KF, Marco J, Rothbaum D, O'Keefe J, et al. Implications of recurrent ischemia after reperfusion therapy in acute myocardial infarction: a comparison of thrombolytic therapy and primary angioplasty. $f$ Am Coll Cardiol 1995;26:66-72.

4 Rapaport E, Remedios P. The high risk patient after recovery from myocardial infarction: recognition and management. $\mathcal{F}$ Am Coll Cardiol 1983;1:391-400.

5 DeBusk RF, Kraemer HC, Nash E, Lew H. Stepwise risk stratification soon after acute MI. Am f Cardiol 1983;52: 1161-6.

6 Moss AJ, Benhorn J. Prognosis and management after a firs myocardial infarction. N Engl f Med 1990;322:743-53.

7 Theroux P, Waters DD, Halphen C, Debaisieux JC, Mizgala JF. Prognostic value of exercise testing soon after myocardial infarction. N Engl f Med 1979; 301:341-5.

8 Sami M, Kraemer H, De Busk RF. The prognostic significance of serial exercise testing after myocardial infarction. Circulation 1979; 60:1238-46.

9 Starling MR, Crawford MH, Kennedy GT, O'Rourke RA Exercise testing after myocardial infarction: predictive value for subsequent unstable angina and death. Am $7 \mathrm{Car}$ value for subsequent
diol $1980 ; 46: 909-14$.

10 Weld FM, Chu K-L, Bigger JTJ, Rolnitzky LM. Risk stratiWeld FM, Chu K-L, Bigger JTJ, Rolnitzky LM. Risk strati-
fication with low-level exercise testing 2 weeks after acute fication with low-level exercise testing 2 weeks aft

11 DeBusk RF. Specialized testing after recent myocardial infarction. Ann Intern Med 1989;110:470-81.

12 Gibson RS, Watson DD, Craddock GB, Crampton RS, Kaiser DL, Denny MJ, et al. Prediction of cardiac events afte uncomplicated myocardial infarction: a prospective study comparing predischarge exercise thallium-201 scintigraphy and coronary angiography. Circulation 1983;68:321-36.
13 Hung J, Goris ML, Nash E, Kraemer HC, De Bush RF, Berger WE, et al. Comparative value of maximal treadmill testing, exercise thallium myocardial perfusion scintigraphy and exercise radionuclide ventriculography for distinguishing high- and low-risk patients soon after acute myocardial infarction. Am f Cardiol 1984;53:1221-7.

14 Legrand V, Rigo P, Kulbertus HE. Complementary role of thallium-201 scintigraphy to pre-discharge exercise electrocardiography for patient stratification after a first myocardial infarction. Eur Heart $\mathcal{F}$ 1986;7:644-53.

15 Leppo JA. Dipyridamole-thallium imaging: the lazy man's stress test. F Nucl Med 1989;30:281-7.

16 Beer SG, Heo J, Iskandrian AS. Dipyridamole thallium imaging. Am f Cardiol 1991;67:18-26D.

17 Leppo JA, O'Brien J, Rothendler JA, Getchell JD, Lee VW. Dipyridamole-thallium-201 scintigraphy in the prediction of future cardiac events after acute myocardial infarction. $N$ Engl f Med 1984;310:1014-8

18 Pirelli S, Inglese E, Suppa M, Corrada E, Campolo L. Dipyridamole-thallium 201 scintigraphy in the early post-infarction period. (Safety and accuracy in predicting the extent of coronary disease and future recurrence of angina in patients suffering from their first myocardial infarction.) Eur Heart f 1988;9:1324-31.

19 Younis LT, Byers S, Shaw L, Barth G, Goodgold H, Chaitman BR. Prognostic value of intravenous dipyridamole thallium scintigraphy after an acute myocardial ischemic event. Am 7 Cardiol 1989;64:161-6.

20 Gimple LW, Hutter AM, Guiney TE, Boucher CA. Prognostic utility of predischarge dipyridamole-thallium imaging compared to predischarge submaximal exercise electrocardiography and maximal exercise thallium imaging after uncomplicated acute myocardial infarction. $\mathrm{Am} \mathcal{F}$ Cardiol 1989;64:1243-8.

21 Brown KA, O'Meara J, Chambers CE, Plante DA. Ability of dipyridamole-thallium-201 imaging one to four days after acute myocardial infarction to predict in-hospital and late recurrent myocardial ischemic events. Am 7 Cardiol 1990;65:160-7.

22 Smart RC, Burke JJ, Lyons NR. Thallium circumferential profiles in the detection of coronary artery diseaseassessment by receiver operating characteristic curve analysis. Eur f Nucl Med 1986;12:9-15.

23 Hutton BF, Cormack J, Fulton RR. A software package for the analysis of gated blood pool studies. Aust Phys Eng Sci Med 1982;5:128-34

24 Mahmarian JJ, Pratt CM, Nishimura S, Abreu A, Verani MS. Quantitative adenosine $201 \mathrm{Tl}$ single-photon emission computed tomography for the early assessment of patients surviving acute myocardial infarction. Circulation 1993;87: 1197-210.

25 Bonow RO, Dilsizian V. Assessing viable myocardium with thallium-201. Am 7 Cardiol 1992;70:10-17E.

26 Dilsizian V, Rocco TP, Freedman NMT, Leon MB, Bonow RO. Enhanced detection of ischemic but viable myocardium by the reinjection of thallium after stressdium by the reinjection of thallium after stress
redistribution imaging. $N$ Engl f Med 1990;323:141-6.

27 Schuster EH, Bulkley BH. Early post-infarction angina: ischemia at a distance and ischemia in the infarct zone. $N$ Engl f Med 1981;305:1101-5.

28 Abraham RD, Freedman SB, Dunn RF, Newman H, Roubin RS, Harris PJ, et al. Prediction of multivessel coronary artery disease and prognosis early after acute myocardial infarction by exercise electrocardiography and thallium-201 myocardial perfusion scanning. Am $\mathcal{F}$ Cardiol 1986;58:423-7.

29 Satler LF, Pallas RS, Bond OB, Green CE, Pearle DL, Schaer GL, et al. Assessment of residual coronary artery stenosis after thrombolytic therapy during acute myocardial infarction. Am f Cardiol 1987;59:1231-3.

30 The TIMI Study Group. Comparison of invasive and conservative strategies after treatment with intravenous tissue plasminogen activator in acute myocardial infarction: results of the Thrombolysis in Myocardial Infarctio (TIMI) phase II trial. $N$ Engl F Med 1989;320:618-27.

31 Iskandrian AS, Heo J, Askenase A, Segal BL, Helfant RH Thallium imaging with single photon emission computed tomography. Am Heart f 1990;110:135-43. 